\title{
DEVELOPMENT AND VALIDATION OF A GRADIENT HPLC METHOD FOR QUANTIFICATION OF EDETATE DISODIUM IN LYOPHILIZED INJECTABLE DRUG PRODUCT
}

\author{
SHRIPAD DESHPANDE ${ }^{1}$, MAZAHAR FAROOQUI², GAJANAN GANAP ${ }^{1}$ VISHAL KHADKE $^{3}$, D. D. KAYANDE ${ }^{*}$ \\ ${ }^{1}$ S. B. E. S. College of Science, Aurangabad, Maharashtra, India 431001, ${ }^{2}$ Dr. Rafiq Zakaria College for Women, Aurangabad, Maharashtra \\ India 431004, ${ }^{3}$ ICICI knowledge park Shameerpet, Hyderabad, 500078 India \\ Email: Drkayande@gmail.com
}

Received: 14 Feb 2019, Revised and Accepted: 11 Apr 2019

\section{ABSTRACT}

Objective: The present study was aimed to validate a developed reversed phase gradient high-performance liquid chromatography method for the quantitative determination of Edetate Disodium in the lyophilized injectable drug product.

Methods: The amount of total Edetate disodium was analysed by HPLC assay using Edetate disodium USP as a reference standard. Injectable product was dissolved in acetone and Edetate disodium is separated out from API and then dissolved in water. Analysis was carried out using ferric chloride as a precolumn derivatizing reagent and YMC Pack ODS-A, $5 \mu \mathrm{m}$ column with mobile phase as a mixture of tetrabutylammonium bromide buffer $\mathrm{pH} 2.8$ and acetonitrile as the solvent, water used as diluent. The Edetate disodium quantified by U. V. wavelength at $254 \mathrm{~nm}$.

Results: The method was suitably validated with respect to specificity, linearity, precision, accuracy and solution stability, using this method the average recovery from spike sample is $98.2 \%$, with a relative standard deviation of $<3 \%$. The minimal quantifiable level was $1.5 \mu \mathrm{g} / \mathrm{ml}$. The results show that the procedure is accurate, precise and reproducible.

Conclusion: In the present study an attempt has been made to develop and validate the analytical method for lyophilised injectable formulations and to generate the scientific database for formulation and evaluation of various lyophilised injectable containing Edetate disodium.

Keywords: HPLC, Edetate disodium, Ferric chloride, Method validation

(C) 2019 The Authors. Published by Innovare Academic Sciences Pvt Ltd. This is an open-access article under the CC BY license (http://creativecommons.org/licenses/by/4.0/) DOI: http://dx.doi.org/10.22159/ijcpr.2019v11i3.34093

\section{INTRODUCTION}

Disodium edetate is a disodium salt of ethylenediaminetetraacetic acid (EDTA). It is a white crystalline powder, soluble in water. It forms stable and water-soluble complexes with various metal ions and also used in the treatment of metal poisoning as a decontaminating agent $[1,2]$. EDTA in its disodium salt or calcium disodium salt form is frequently used in pharmaceuticals because of its stability, compatibility and low toxicity a relatively nontoxic chelating agent can be defined as a substance whose molecules can form several bonds to a single metal ion that is used to remove divalent metal ions, aid the action of preservatives and antibacterial, and stabilize the action of antioxidants [3]. Its stability, compatibility, and low toxicity account for its wide use in ophthalmic and contact lens care solutions. Chelation therapy using EDTA is medically accepted treatment for lead poisoning and digoxin toxicity.

There are several methods presently available to measure Disodium Edetate. These include colorimetry $[4,5]$, photometry [6], spectrophotometry [6-8], titration [9-14], TLC [15, 16], GC [17, 18], HPLC $[19,20]$ and ion chromatography [21-23]. However some of these methods require extensive sample workup, including the use of hazardous derivatizing reagent, some are not sufficiently sensitive to permit reproducible quantitation at normal sample concentrations, and others are neither technically nor economically feasible for routine use in most analytical and quality assurance laboratories. The gas chromatographic methods always include time-consuming derivatization steps, in which EDTA is converted into methyl, ethyl, propyl and butyl esters to obtained volatility. Although many of the chromatographic methods offer the advantage of being specific, most require large sample volumes in order to maintain reasonable accuracy and reproducibility.

As EDTA does not contain any chromophoric group, it is very difficult to determine EDTA by direct UV detection. The aim of this study describes the development and validation of the pre-column derivatization analytical method with direct UV-detection for the quantitative determination of Disodium Edetate in the lyophilised injectable drug product. Also to show that the study has advantages over some techniques as mentioned in above references, like here EDTA response is measured by direct UV detection with enhanced sensitivity and method is simpler, highly reproducible, specific and accurate, compare to using complex techniques like titrimetric, spectrophotometric, capillary electrophoresis or GC technique. The method has been optimized with respect to reaction time and derivatization reagent volume and suitably validates for its intended use. The applicability of the method is illustrated for several typical samples.

\section{MATERIALS AND METHODS}

Tetrabutylammonium bromide was purchased from SIGMAALDRICH. Acetonitrile and Methanol were purchased from Merck. Purified water was obtained from Milli-Q water system (Millipore Corp). The lyophilized injectable product was obtained from precise chromatography for development purpose. Disodium Edetate (fig. 1) was purchased from Merck. Ferric chloride was purchased from Merck. All chemicals were used as such and provided by the manufacturer, no further purification has been done. All the other chemicals were of analytical grade. Magnetic stirrer, cyclomixer, microcentrifuge bought from Eppendorf Equipment's Pvt. Ltd. was used. HPLC from Waters, used in the analysis of the drug. Bath sonicator from PCI Analytics brand was used.

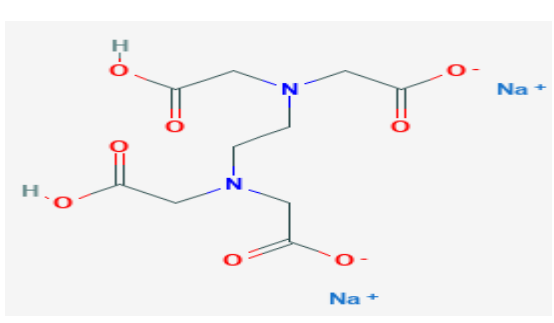

Fig. 1: Structure of disodium edentate 


\section{Chromatographic system and condition}

The HPLC system consists of a water 2489 module, including quaternary pump, auto-sampler with thermostat, column oven, coupled with a multiple wavelength or diode array UV detectors. YMC Pack C18 (4.6 mm $250 \mathrm{~mm}, 5 \mu$ ) analytical columns were used for method development and validation. The Empower 3 chromatographic Software was used for data acquisition and processing. The mobile phase A is consisted of a buffer $\mathrm{pH} 2.8$ prepared by dissolving $1 \mathrm{gm}$. of tetrabutylammonium bromide in $1000 \mathrm{ml}$ of water and mixed; $\mathrm{pH}$ of the buffer was adjusted to 2.8 with the diluted phosphoric acid solution. The mobile phase B consists of buffer and acetonitrile in the ratio of (10:90). The wavelength selected at $254 \mathrm{~nm}$, injection volume kept as $20 \mu \mathrm{l}$. Sampler cooler was kept at $5{ }^{\circ} \mathrm{C}$. The analytical column theoretical plate number and tailing factor of the analytes under different chromatographic conditions were calculated using USP methods. Binary solvent gradient was applied at a flow rate of $1.0 \mathrm{ml}$ min-1 and programmed as follows: $82 \%$ mobile phase $\mathrm{A}$ and $18 \%$ mobile phase $\mathrm{B}$ at $0 \mathrm{~min}$ to $15 \mathrm{~min}$., progressing linearly at $10 \%$ mobile phase $A$ and $90 \%$ mobile phase $B$ at 16 min, followed by the hold in the mobile phase A to $10 \%$ and mobile phase B to $90 \%$ at $20 \mathrm{~min}$., finally returning to the initial gradient and flow at $21 \mathrm{~min}$ and maintained at this composition and flow for $10 \mathrm{~min}$ in the total time of 30 min of analysis.

\section{Preparation of ferric (III) chloride and blank solution}

Ferric chloride (III) stock solution is prepared by transferring about $65 \mathrm{mg}$ of Ferric (III) chloride anhydrous into $200 \mathrm{ml}$ amber colour volumetric flask Added $80 \mathrm{ml}$ of water and dissolved. Amber colour flask was taken to avoid the oxidation. Make up the volume with water and mix. Accurately transfer $5 \mathrm{ml}$ of water into $25 \mathrm{ml}$ of volumetric flask and add $5 \mathrm{ml}$ of Ferric (III) chloride solution. Keep the flask at room temperature for $30 \mathrm{~min}$. and make up the volume with water and mixed well.

\section{Preparation of edetate disodium standard stock solution}

A standard stock solution at $0.1(\mathrm{mg} / \mathrm{ml})$ was prepared by dissolving about $20 \mathrm{mg}$ of Disodium Edetate into $200 \mathrm{ml}$ volumetric flask, added about $120 \mathrm{ml}$ of diluent, sonicate to dissolve. Makeup to the mark with diluent and mix well.

\section{Preparation of lyophilized injectable product sample (stock)}

1. Randomly selected the five vials of lyophilized injectable product and removed the flip off seal.

2. Removed the air from the vials by inserting the needle into the center of the rubber stopper.

3. Carefully transferred content from five vials into the clean and dry beaker. Rinsed the individual five vials with $2 \mathrm{ml}$ of acetone along with its stopper.

4. Transferred entire content from beaker to centrifuge tube. Rinsed the beaker with about 2-3 $\mathrm{ml}$ of acetone and transferred the rinsed solution in the centrifuge tube. Centrifuge the solution for 10 min. at 5000 RPM. Sediment mass was observed at the bottom of the centrifuge tube.

5. Decanted the supernatant solution without disturbing the sediment mass. Added $10 \mathrm{ml}$ of water into the centrifuge tube and sonicate to dissolve the sedimented mass. Transferred the content into $50 \mathrm{ml}$ volumetric flask by using a funnel. Rinsed the centrifuged tube with 7-8 ml of water for 3 more times and transferred to $50 \mathrm{ml}$ volumetric flask. Made up the volume with water and mixed.

\section{Derivatization procedure for standard and sample solution}

Each $5.0 \mathrm{ml}$ of standard and sample stock solution is transferred to a $25 \mathrm{ml}$ of separate volumetric flask and $5.0 \mathrm{ml}$ of ferric chloride is added to it, the solutions are kept at room temperature for $30 \mathrm{~min}$. on the bench top and further diluted with diluent and injected on HPLC.

\section{Specificity and selectivity}

To assure the specificity of the proposed method, the Edetate disodium solution is prepared in diluent with and without excipients used in the lyophilised product. Also blank and impurity degraded at various conditions, All samples injected in HPLC and checked for its interference (table 1 ).

Table 1: Specificity for edetate disodium

\begin{tabular}{llll}
\hline S. No. & Name of the solution & No. of injection & Retention time \\
\hline 1 & Blank & 1 & NA \\
2 & Placebo & 1 & NA \\
3 & Standard solution (Disodium Edetate) & 1 & 8.313 \\
4 & Sample solution (API) & 1 & 19.219 \\
5 & Related impurity-1 & 1 & 19.484 \\
6 & Related impurity-2 & 1 & 19.306 \\
\hline
\end{tabular}

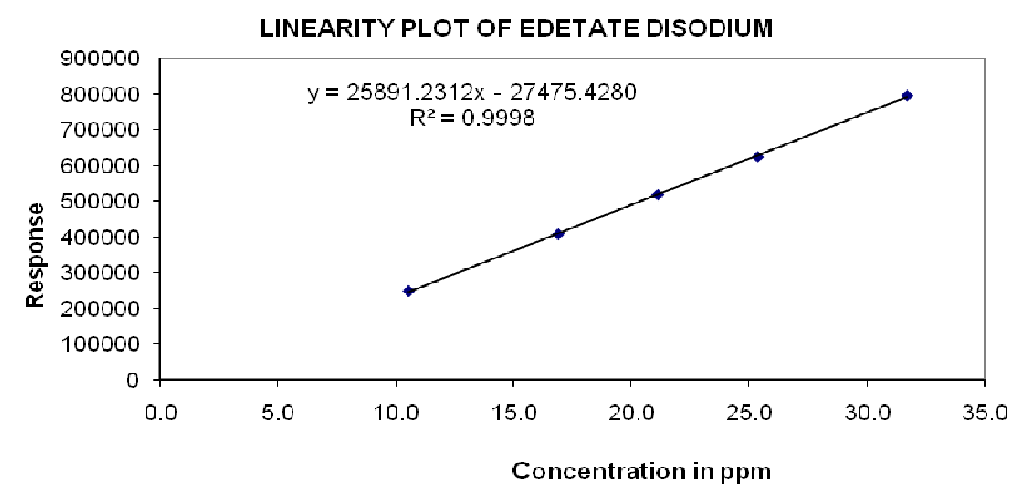

Fig. 2: Linearity plot edetate disodium

\section{Linearity, accuracy and precision}

To establish the linearity of the proposed method, a series of edetate disodium solution $(10-30 \mu \mathrm{g} / \mathrm{ml})$ were prepared from the stock solution and analyzed. The relationship between EDTA concentration and detector response was evaluated to confirm linearity. EDTA standards at five different concentrations encompassing a minimum of $80-120 \%$ of the expected concentration of EDTA in the lyophilized product were included in the study (fig. 2, table 2). 
Table 2: Linearity concentration and response for edetate disodium

\begin{tabular}{lllll}
\hline S. No. & Target level (\%) & Concentration $(\boldsymbol{\mu g} / \mathbf{m l})$ & Area-1 & Area-2 \\
\hline 1 & 50 & 10.0 & 249402 & 248652 \\
2 & 80 & 16.0 & 409653 & 407488 \\
3 & 100 & 20.0 & 518878 & 519446 \\
4 & 120 & 24.0 & 625175 & 625337 \\
5 & 150 & 30.0 & 799186 & 795434 \\
Slope & & & & \\
Correlation coefficient & & & \\
R & & & \\
\% Y-intercept & & & \\
\end{tabular}

The accuracy of the method is the closeness of measured value to true value. To determine the accuracy, different levelsofedetate disodium prepared by weighing and adding it to the placebo and analysed. The accuracy was calculated as the percentage recovery (table 3).

Table 3: Accuracy for edetate disodium

\begin{tabular}{|c|c|c|c|c|c|}
\hline S. No. & Target level & Average area & Amount drug added $(\mu \mathrm{g} / \mathrm{ml})$ & Amount of drug found $(\mu \mathrm{g} / \mathrm{ml})$ & \% Recovery \\
\hline 1 & $50 \%$ sample-1 & 236665 & 2.626 & 2.504 & 95.35 \\
\hline 2 & $100 \%$ sample-2 & 478071 & 5.074 & 5.058 & 99.68 \\
\hline 3 & $100 \%$ sample- 3 & 482472 & 5.166 & 5.104 & 98.8 \\
\hline 4 & $100 \%$ sample- 1 & 468848 & 5.126 & 4.96 & 96.8 \\
\hline 5 & $150 \%$ sample- 2 & 733740 & 7.749 & 7.762 & 100.2 \\
\hline Mean & & & & & 98.2 \\
\hline SD & & & & & 2.039 \\
\hline$\%$ RSD & & & & & 2.08 \\
\hline
\end{tabular}

The precision of the analytical method was evaluated by system precision (table 4) and repeatability (intra-day) (table 5) and intermediate precision (inter-day) (table 6). The repeatability was done by analysing three samples of lyophilised injectable product (duplicate injection of each). The same process was repeated on the second day to assess intermediate precision using three freshly prepared sample solutions. The precision was measured by the \% RSD of the duplicate injections for each of the three samples.

Table 4: Precision-system precision for Edetate disodium

\begin{tabular}{lll}
\hline S. No. & Standard area response (day-1) & Standard area response (day-2) \\
\hline 1 & 538589 & 536588 \\
2 & 532506 & 528879 \\
3 & 531503 & 531003 \\
4 & 534242 & 526599 \\
5 & 533621 & 531108 \\
6 & 522727 & 53228 \\
Mean & 532198 & 531077.3 \\
SD & 5240.7 & 3368.2 \\
$\%$ RSD & 0.98 & 0.63 \\
\hline
\end{tabular}

Table 5: Method precision (M. P.)-Intra-day

\begin{tabular}{|c|c|c|c|c|c|}
\hline S. No. & Sample name & Area & Average area & Amount of $\mathrm{mg} / \mathrm{ml}$ & \% Drug assay \\
\hline \multirow[t]{2}{*}{1} & M. P. Sample 1-1 & 487708 & 487310 & 0.968 & 96.8 \\
\hline & M. P. Sample 1-2 & 486912 & & & \\
\hline \multirow[t]{2}{*}{2} & M. P. Sample 2-1 & 490987 & 489693 & 0.973 & 97.3 \\
\hline & M. P. Sample 2-2 & 488399 & & & \\
\hline \multirow[t]{2}{*}{3} & M. P. Sample 3-1 & 485793 & 483763 & 0.961 & 96.1 \\
\hline & M. P. Sample 3-2 & 483763 & & & \\
\hline Mean & & & & & 96.7 \\
\hline SD & & & & & 0.60 \\
\hline$\%$ RSD & & & & & 0.62 \\
\hline
\end{tabular}

Table 6: Method precision (I. P.)-inter-day

\begin{tabular}{lllll}
\hline S. No. & Sample name & Area & Average area & Amount of mg/ml \\
\hline 1 & I. P. Sample 1-1 & 503767 & 501838 & 0.959 \\
& I. P. Sample 1-2 & 499908 & & \\
2 & I. P. Sample 2-1 & 496790 & 497290 & 0.955 \\
& I. P. Sample 2-2 & 497789 & & 95.9 \\
3 & I. P. Sample 3-1 & 505098 & 505098 & 0.970 \\
& I. P. Sample 3-2 & 498909 & & 97.0 \\
Mean & & & & \\
SD RSD & & & & 0.78 \\
\hline
\end{tabular}




\section{RESULTS AND DISCUSSION}

The developed method was observed to be linear in the range of 10$30 \mu \mathrm{g} / \mathrm{ml}$. The calibration curve was constructed by using the linear regression equation. The regression equation was originating y $=25891.2312 x-27475.4280$. The correlation coefficient $\left(r^{2}\right)$ of the regression curve was found to be 0.9998 .

In specificity experiment, no peak is observed at the retention time of Edetate Disodium peak from blank, placebo, degraded sample and related impurities. Hence it can be said that the proposed analytical method is specific and selective for the determination of edetate disodium.

The average percentage recoveries of EDTA in the spiked samples at three different levels ranged from $95.4 \%$ to $100.2 \%$ with an overall average of $98.2 \%$. The percentage of relative standard deviation (\%RSD) for the triplicate measurements at each level was less than $3 \%$. Which demonstrated a high level of accuracy.

Precision was also determined by repeatability and intermediate precision. It was found that the system precision was $0.98 \%$ on day1 and $0.63 \%$ on day- 2 . The method precision was $0.62 \%$ on day- 1 and $0.81 \%$ on day- 2 these data demonstrated the acceptable precision of the method. The RSD value found is well within the acceptable range indicating that the proposed method may be considered validated in term of precision.

\section{CONCLUSION}

The simplicity, specificity, and versatility of this method have been shown through experiments conducted on the lyophilised injectable product. The method was validated and shown to be precise, accurate, and reproducible. The method should be readily adaptable to the analytical needs of the pharmaceutical and cosmetics industry. The proposed method is found to be highly sensitive; therefore it could be used for routine analysis for determination of Disodium Edetate content.

\section{ACKNOWLEDGMENT}

The facilities provided by the ICICI Knowledge Park, is gratefully acknowledged.

\section{AUTHORS CONTRIBUTIONS}

The entire author contributed equally

\section{CONFLICT OF INTERESTS}

Declare none

\section{REFERENCES}

1. Cranton EM, Frackelton JP. Scientific rationale for EDTA chelation therapy mechanism of action. Virginia: Hampton Roads publishing Company; 2001.

2. Hawken CM. Chelation therapy: an effective method for maintaining cardiovascular health, history of EDTA and chelation therapy. Texas: Woodland publishing; 1997.

3. Nema S, Brendel RJ. Excipients and their role in approved injectable products: current usage and future directions. PDA J Pharm Sci Technol 2011;65:287-332.

4. Domingo JL. Developmental toxicity of metal chelating agents. Reprod Toxicol 1998;12:400-510.
5. Saito K, Hasuo T, Nakano H. Nippon jozo kyokai zasshi determination and differentiation of ethylenediaminetetraacetic acid (EDTA) and nitrilotriacetic acid (NTA) in fresh water. Water Res 1968;63:1193-7.

6. Laine P, Matilainen R. Simultaneous determination of DTPA, EDTA and NTA by UV spectrometry and HPLC. Anal Bioanal Chem 2005;382:1601-9.

7. Kaiser KLE. Removal of some chelators from aqueous solutions using polymeric ingredients. Water Res 1973;7:1465-73.

8. Nemocova I, Pesinova H, Suk V. Analysis of aminopolycarboxylates and organophosphonates. Microchem 1984; 30:27-32.

9. Nikolelis DP, Hadjiioannou TP. All-solid-state potentiometric sensors for ascorbic acid by using a screen-printed compatible solid contact. Anal Chim Acta 1978;97:111-20.

10. Qureshi SZ, Bansal R, Fresenius Z. Cation-exchange method for the detection of pyrrole derivatives. Anal Chem 1981;308:32.

11. Qureshi SZ, Bansal R. Analysis of aminopolycarboxylates and organophosphonates; 1984;12:42-4.

12. Blijenberg BG, Leijnse B. A simple method for the determination of EDTA in serum and Urine. Chim Acta 1969;26:577-9.

13. Huber CO, Tallant DR. Voltammetry at the lead dioxide electrode: anodic EDTA currents. J Electroanal Chem Interfacial Electrochem 1968;18:421-5.

14. Milwidsky BM. Determination and differentiation of ethylenediaminetetra-acetic acid (EDTA) and nitrilotriacetic acid (NTA). Soap Cosmet Chem Spec 1971;47:46, 49.

15. Slowinski EJ, Masterton WL, Wolsey WC. Chemical principles in the laboratory. WB Saunders: Philadelphia; 1969. p. 506-7.

16. Fitzgerald EA. Phenacyl esters of fatty acids via crown ether catalysts for enhanced ultraviolet detection in liquid chromatography. Anal Chem 1975;47:356-7.

17. Parkes DG, Caruso MG, Spradling JE. Determination of nitrilotriacetic acid in ethylenediaminetetraacetic acid disodium salt by reverse-phase ion-pair liquid chromatography. Anal Chem 1981;53:2154-6.

18. U. S. Pharmacopeia. 21st Rev, US. Pharrnacopeial Convention: Rockville, MD; 1985. p. 368-9.

19. Venezky DL, Rudzinski WE. Handbook of detergents, part c. Anal Chem 1984;56:315-7.

20. Yamaguchi A, Rajput AR, Ohzeki K, Kambara T. Determination of EDTA in vancomycin by liquid chromatography with absorbance ratioing for peak identification. Bull Chern Soc J 1983;56:2621-23.

21. Fitchett AW, Woodruff A. Analysis of aminopolycarboxylates and organophosphonates liq. Chromatogram HPLC Mag 1983;1:48-9.

22. Yamaguchi A, Ohzeki K, Kambara T, Fresenius' Z. Determination of trace amounts of EDTA by use of a CuOloaded cation exchanger. Anal Chem 1982;310:30-2.

23. Bauer J, Heathcote D, Krogh SJ. Quantitative determination of disodium Edetate in ophthalmic and contact lens care solution by reverse-phase high-performance chromatography. J Pharma Sci 1986;369:422-5.

24. www.drugbank.com [Last accessed on 10 Jan 2019]

25. www.sciencedirect.com [Last accessed on 10 Jan 2019]

26. www.pubmed.com [Last accessed on 10 Jan 2019]

27. www.mhra.gov.uk [Last accessed on 10 Jan 2019]

28. International conference on harmonization of technical requirements for registration of pharmaceuticals for human use. ICH Guideline Q2 (R1); 1995.

29. USP 41-NF 36 Online Table of Contents: Admissions; 2007. 